\title{
In the Classroom
}

\section{A Task-Based Language Teaching Approach to the Police Traffic Stop}

\author{
Stephen P. O'Connell
}

One possible hurdle to implementing the Task-Based Language Teaching (TBLT) approach is uncertainty about how to turn target tasks into materials that can be used in the classroom. This article discusses the steps taken to create materials for one target task (communicating with a police officer during a traffic stop) in a manner that provides a framework for others who wish to create materials for target tasks to follow. Specifically, the discussion will focus on how information was obtained from domain experts (police officers) and how samples of target discourse were collected. It will then explain how that information was turned into prototypical dialogues, which then serve as the foundation for pedagogic tasks that can be used to help learners achieve the goal of communicating with police officers during traffic stops. By explaining how prototypical dialogues were developed for this target task, it is believed that some of the uncertainty about how to turn the theory of TBLT into something concrete for learners will be alleviated.

Un élément qui pourrait constituer un obstacle à la mise en auvre de l'enseignement des langues basé sur les tâches (ELBT) est l'incertitude quant à la façon de transformer les tâches cibles en matière utilisable dans la salle de classe. Cet article discute des démarches entreprises pour créer du matériel pour une tâche cible (communiquer avec un agent de police lors d'un contrôle routier), de sorte à fournir un cadre pour ceux et celles qui voudraient élaborer du matériel pour d'autres tâches cibles. Plus précisément, la discussion portera sur l'obtention d'informations d'experts du domaine (des agents de police) et sur la collecte d'échantillons de discours cibles. Suivra une explication sur la transformation de ces informations en dialogues prototypiques qui deviennent ensuite la base de tâches pédagogiques visant à aider les élèves à communiquer avec des agents de police pendant les contrôles routiers. En expliquant le développement de dialogues prototypiques pour cette tâche cible, nous croyons réduire une part de l'incertitude relative à la transformation de la théorie de l'ELBT en matière concrète pour les apprenants.

In the introduction to Task-Based Language Education: From Theory to Practice, Van den Branden (2006) asks rhetorically, "Can [Task-Based Language Teaching; TBLT] really inspire language teachers when they prepare their lessons or does it only frighten them because of the high demands it places on them 
and their learners?" (pp. 1-2). Part of the demand that van den Branden refers to is in regard to materials preparation; he writes explicitly in his chapter in Task-Based Language Teaching: A Reader that one of the challenges that TBLT faces is that "implementation (both small scale and large scale) inevitably poses problems of innovation" (Van den Branden, Bygate, \& Norris, 2009, p. 11). Although much has been written about the theory of TBLT and about relationships between task-types and language production, little is available on the more practical aspect of implementation. This article attempts to address this gap in two ways, by (a) providing suggestions for teaching materials for a specific target task identified for a specific community of English learners, and (b) explaining the steps taken to create the teaching materials in a manner that will allow their application to other target tasks.

Before beginning, however, it is necessary to explain what exactly is meant by the terms target tasks, pedagogic tasks, and materials. Target tasks are the realworld activities that learners need to be able to do in their second language. Pedagogic tasks are the activities that teachers and learners work on together in the classroom to help learners achieve the goal of successfully managing a target task. The term materials refers broadly to the language objects that are used as the basis for pedagogic tasks, in this case, the prototypical dialogues that were created and the sample dialogues that were collected.

\section{Target Task: \\ Communicating with a Police Officer During a Traffic Stop}

The context for this article is the English as a Second Language (ESL) program of a community centre in a mid-Atlantic state of the United States that provides language, health, employment training, and other services to immigrants (mostly recent arrivals from Central America who speak Spanish as a first language). As an initial step toward implementing TBLT in this organization's ESL program, a needs analysis was conducted using semistructured group interviews (performed in Spanish) and a quantitative survey (Nielsen, 2010). One of the communicative language tasks that the needs analysis revealed to be a high priority for this population-along with such tasks as using mass transportation, buying a cell phone, reading the labels on prescription drugs, communicating with doctors, and speaking with their children's teachers - was communicating with police officers during traffic stops.

\section{Gathering Information on the Target Task}

Once a language-learning need for a group of learners is identified, it is a conscientious instructor's responsibility to address that need as best as he or she can. In such situations, a language instructor's first inclination will often be to turn to commercially available textbooks. However, if the target task in question is addressed in sample dialogues or materials in a textbook, the 
language modelled is often too generic and bears little resemblance to what is used in real-life interactions to be of much use to learners (see Bartlett, 2005; Granena, 2008; Wong, 2002). The dialogues and reading passages are often thinly disguised vehicles for practicing grammatical structures. At best, they describe how someone else performed a target task, which is very different from putting learners into the position of learning to perform it themselves. For the police traffic stop target task, six ESL textbooks were examined; only two included a reference to interacting with police officers in any situation and only one contained a reference to traffic stops. However, the language of a traffic stop was not modelled, so the content would be of little use to learners trying to learn how to cope with an actual traffic stop situation.

To create the type of practice opportunities that might lead to language acquisition (Gass, 1997; Gass \& Mackey, 2007; Long, 1996; Mackey, Gass, \& McDonough, 2000; McDonough, 2005) and the competence to perform a task, one needs examples of it being performed. Reliable information about the current target task, that is, finding out what police officers need drivers to be able to communicate and the questions police officers generally ask during a traffic stop, is unlikely to come from any source other than police officers themselves. Furthermore, communicating with police officers during a traffic stop is a potentially high-stakes situation. ${ }^{1}$ A person who is stopped for a traffic or vehicle equipment violation needs to be able to provide certain information, ascertain why they have been stopped, and the outcome. Therefore, using intuition and information from secondary sources to prepare learners for this type of situation seems an even poorer idea than usual when preparing language teaching materials. ${ }^{2}$ Instead, the author turned to domain experts, who are generally the best sources of information (Long, 2005, 2014). Five area police departments were contacted. Four ${ }^{3}$ responded to the author's request for information about the types of questions police officers are likely to ask during a traffic stop. They provided sample scripts of the dialogues their officers generally followed (or were trained to follow) when making a traffic stop. This information is summarized in Table 1. Additionally, one department made its traffic safety officer available for an hour-long interview with the author to provide further information about what traffic stops entail and what drivers should be able to communicate. ${ }^{4}$

Table 1 shows that there are some commonalities in what the different police departments expect or train their police officers to say during traffic stops. The request for license and registration (Move 3) is seen in all five scripts. A request to remain seated and inside the vehicle (Move 10) is contained in four of the five scripts, and although it is not included in the fifth script provided by one of the officers that the author observed, when actually conducting traffic stops, this officer did in fact tell drivers to remain seated. However, beyond those two commonalities, much of the rest of the set dialogue that an officer delivers will depend on the circumstances. For example, Scripts 1, 2, and 4 all contained follow-up questions about the ownership 


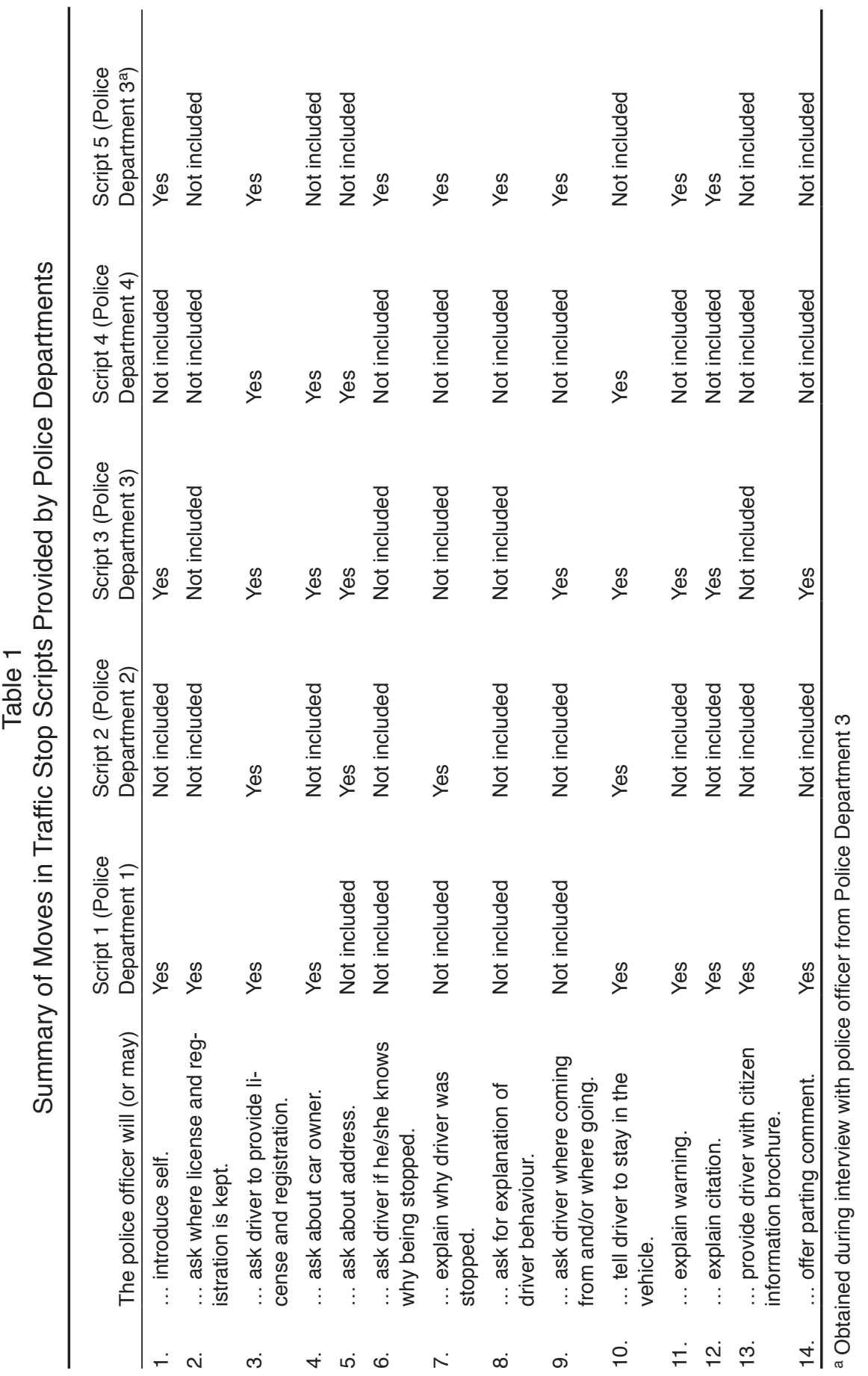


of the vehicle, which would only be asked if the name of the driver and the name on the vehicle registration did not match. Due to the discourse being dependent on the circumstances, we see that Scripts 2 and 3 do not branch into the varied language used regarding the issuing of a warning, as opposed to a citation.

The scripts also indicate that there are not a lot of questions for a driver to answer in the typical traffic stop. When the eight target discourse samples of actual traffic stops (discussed below) were examined, it was revealed that this is what happens in real traffic stops. Once the officers obtain the documents and information they need, they do most of the talking as they explain why the driver was stopped, the outcome of the stop (warning or citation), and how the driver must address the outcome (e.g., no action required for a warning, action required for a citation). In terms of production, the communicative burden on drivers is low, but the need to be able to comprehend what the officer is telling them is high.

\section{Analysis of Target Discourse}

As useful as domain experts are, they should not, if possible, be relied on as the sole source of information regarding how an interaction plays out. Even with domain experts, there is sometimes a disparity between what they think they say or do and what is actually said or done. Therefore, authentic discourse samples are an invaluable source for the creation of materials, such as prototypical dialogues, upon which pedagogic tasks can be based. In the case of traffic stops, obtaining authentic discourse samples proved difficult. Unlike some service encounters (Bartlett, 2005) or academic situations (Hoekje, 2007) that researchers have analyzed, it is unlikely that motorists who have been pulled over will consent to having their encounters recorded for research purposes (although there is no expectation from drivers that their actions or comments are not being recorded by the police officer). Also, unlike routine service encounters or certain academic situations, it is not easy to predict when and where traffic stops will occur.

In order to obtain access to authentic samples of traffic stop discourse, two of the police departments recommended that the author participate in their departments" "ride-along" programs. These are programs that allow a civilian to submit an application to spend a shift with a police officer while he or she is out on patrol. These police departments indicated that although recordings could not be made of the traffic stops, it would be permissible for the author to accompany their officers and to eavesdrop on the conversations they had with the drivers who were pulled over. Thus, on two separate occasions with two separate police departments in Maryland, the author rode along with police officers and witnessed and eavesdropped on eight traffic stops, five with one police officer and three with the other. When the officers stopped vehicles for a moving violation or vehicle equipment violation, the 
author was allowed to exit the police vehicle and eavesdrop on the interaction while standing at the rear passenger-side tire. Immediately upon returning to the police vehicle, a verbatim transcript of the conversation was made, using the police officer as an informant for some of the driver's utterances. More than $90 \%$ of what the officers said was comprehensible; they spoke loudly to assist the author in the task. Depending on the driver and the setting (how busy the road where the stop occurred was), not all of the driver's utterances were heard. However, between what was heard and what the officer reported, and with the use of immediate recall of the interactions, the author feels confident that the transcripts produced adhere extremely closely to how the interactions actually played out. Table 2 summarizes the moves that appeared in the eight traffic stops observed.

Examining these eight samples, it is clear that some commonalities in the discourse exist, and to a degree they match those in the scripts summarized in Table 1. Assuming that nothing out of the ordinary arises (e.g., failure to provide a license), as was the case in these eight samples, the discourse tends to follow a systematic pattern. Officers will probably introduce themselves; will ask for license and registration; may ask for identification from passengers; may ask about ownership of the car; will explain why the driver was stopped; may ask where the driver is going; and may "lecture" the driver, meaning that they may admonish the driver for their violation with the tone of a superior. Finally, officers will explain what the driver is being warned or cited for and will tell the driver what is required of them as a consequence.

There are also differences between the scripts and what was observed. The question regarding where the license is kept (Move 2 in Table 2) did not precede requests for the driver's license, as Script 1 (in Table 1) indicated. Additionally, neither of the officers observed provided drivers with "citizen information brochures" (Move 15 in Table 2). This is possibly because neither of the police officers observed were members of the police department that provided Script 1 . This disparity does underscore, however, the value of obtaining information on a target task from as wide a range of sources as possible. From a learner's perspective, knowing that those questions or conversational moves are potentially part of an officer's repertoire, even though they may not have to respond to them, is better than not being aware of them. The pattern for Move 6 (asking about address) also shows the need for a wide range of samples. The officer who conducted stops 1-5 did not ask any of the drivers to confirm their addresses, whereas the officer who conducted stops 6-8 did ask drivers to verify that information.

Examination of the language of the discourse samples will not only help create prototypical dialogues, but can also help inform specific pedagogic tasks that an instructor employs. The eight samples collected for this research included several lexical items that occurred repeatedly; these repeated lexical items would probably be useful for learners to understand. They in- 


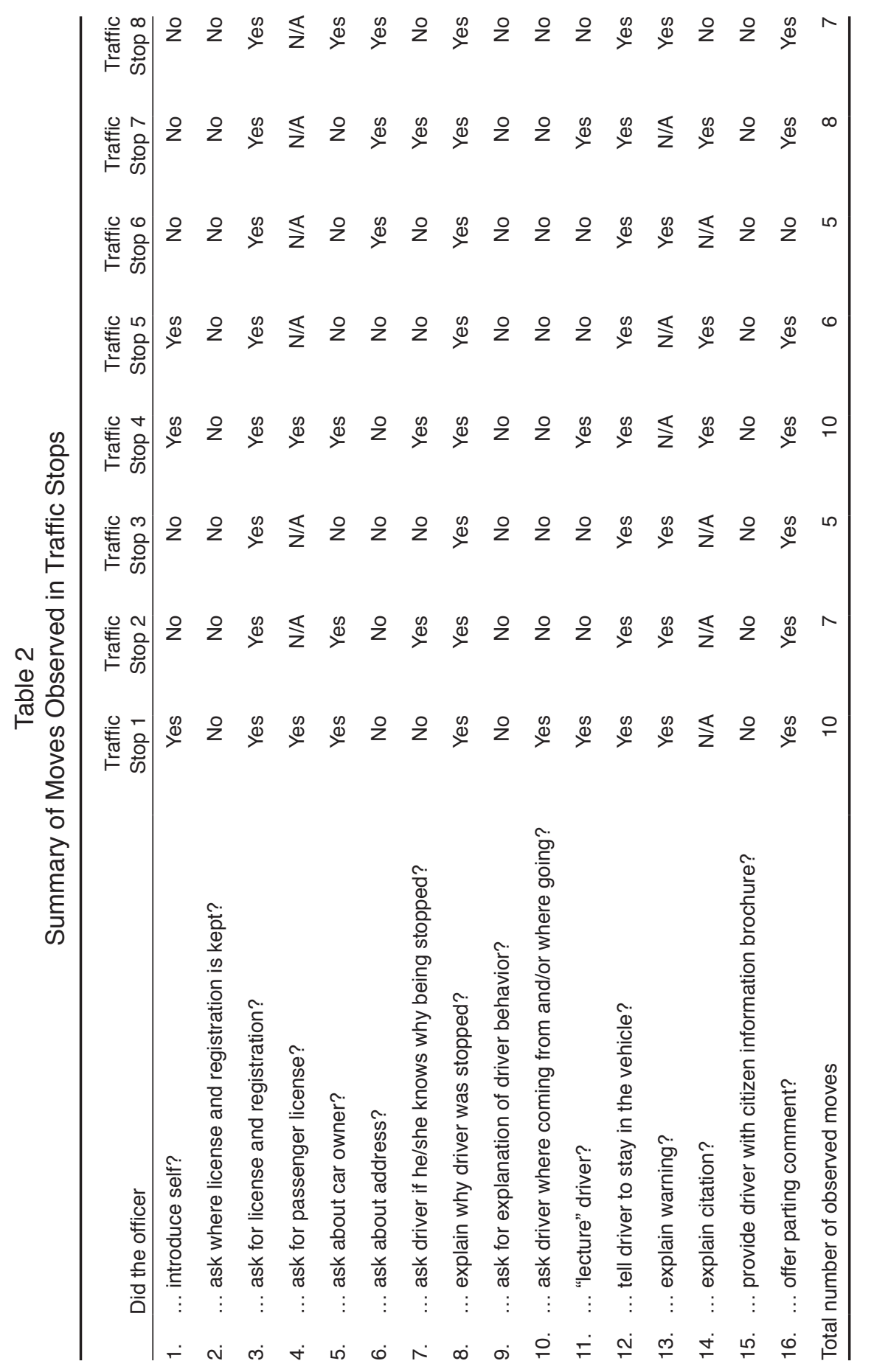


cluded such expressions as "points" (on one's license), "in the system" (a record has been made of the stop), "issuing a warning/citation," and "grant leniency"/"lenient." Although the TBLT approach does not advocate preselecting lexical items to teach learners (i.e., focus on forms), if an instructor has a sense that these lexical items need to have learners' attention drawn to them, they can use input enhancement techniques, such as setting these words in bold or glossing them before they are included in pedagogic tasks.

Additionally, as was mentioned above, the discourse samples showed that police officers do most of the talking during traffic stops. In fact, if a driver can produce his or her license and registration, it is plausible that he or she can get through the interaction by simply nodding and saying "okay" even if they do not understand what is being said. However, this is a tactic that language instructors want to help learners avoid, so the focus of pedagogic tasks for this target task should be aimed at comprehension: understanding why they have been stopped and what the outcome is, as well as practicing requests for clarification.

The information from three sources-the scripts and the interviews (summarized in Table 1) and the traffic stops (summarized in Table 2) is what informs the sample prototypical dialogues (and thus the ensuing pedagogic tasks) that were created for the target task of preparing learners to interact with police officers during a traffic stop. The value of multiple sources and multiple methods of obtaining information from those sources cannot be emphasized enough, as they allow triangulation, which results in the instructor/materials developer having greater confidence that the materials and the pedagogic tasks that are created are relevant and valid (see Long, 2005, 2014).

\section{Prototypical Dialogues and Pedagogic Tasks}

Creating a prototypical dialogue, based on the information gathered and the analysis of target discourse, is one of the first steps when creating pedagogic tasks. The prototypical dialogue should contain the moves that are most common across the observed dialogues, stripped of idiosyncratic turns or topics (for a detailed example of this process, see Bartlett, 2005). However, to increase its naturalness, the prototypical dialogue should draw extensively on the language of the observed dialogues, elaborating where necessary (for the rationale for elaborated, rather than simplified, input, see Long, 2007, 2014). Prior to creating the prototypical dialogue, identifying the linear structure of the discourse that is being examined is recommended. Following the method developed by Ventola (1983) in her analysis of the structure of service encounters, we can demonstrate the pattern that the discourse of the police traffic stop will follow (Figure 1).

With the linear structure established, a materials developer or instructor can then draw on the observed traffic stops to flesh out a prototypical ex- 
change, which will serve as a model for the type of interaction learners need to be able to comprehend and negotiate. The patterns for receiving a warning and receiving a citation in a traffic stop are quite different; therefore, a prototypical dialogue for each is desirable, and might look something like those in Figures 2 and 3.

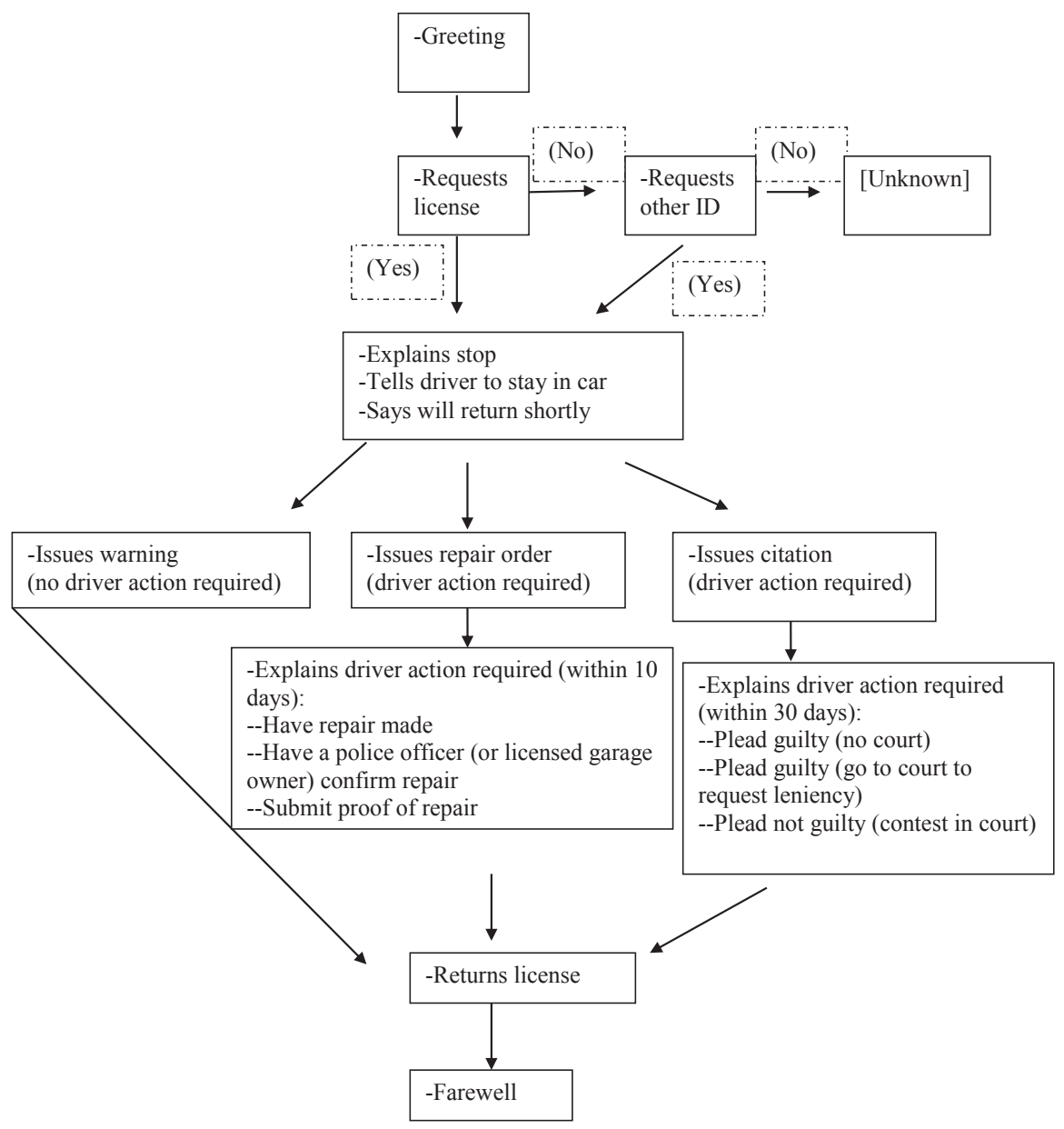

Figure 1: Linear Schematic Structure of the Traffic Stop ${ }^{5}$ 
Officer:

Driver:

Officer:

Driver:

Officer:

Driver:

Officer:

((5-10 minutes))

Officer:

Driver:

Officer:

Driver:

Officer:

Driver:

Officer:
Good evening ma'am. I'm Officer Smith with the Pleasantville Police Department. Can I see your license and registration, please?

Sure, here they are. ((Gives officer documents.)) Okay. And is this still your current address?

Yes, it is.

Okay. Now, I stopped you because one of your brake lights, your left brake light, is out. Were you aware of that?

No, I wasn't.

Okay. Please remain in the car and I'll be back with you in a minute.

Okay, ma'am. I'm giving you a warning on the brake light. ((Gives driver warning.)) You need to get that fixed, though, as it's a violation that you could be cited for. Okay?

Yes, sir, thank you.

And if you're stopped again, the officer will know that you got his warning because it's in the system. So please get that fixed.

Okay.

And here's your license and registration. ((Gives driver documents.))

Thank you.

Have a safe evening, and be careful pulling out here.

Figure 2: Prototypical Dialogue: Warning 
Officer:

Driver:

Officer:

Driver:

Officer:

Driver:

Officer:

Driver:

Officer:

((5-10 minutes))

Officer:

Driver:

Officer:

Driver:

Officer:

Driver:

Officer:
Good evening, sir. I'm Officer Smith with the Pleasantville Police Department. May I see your license and registration, please?

Sure. Here. ((Gives officer documents.))

Okay. And is this still your current address? Yes.

Okay. You know why I stopped you, right?

I was driving over the speed limit?

Yes, you were driving well over the speed limit. I clocked you on the radar gun at 63 - this is a 45-mile-per-hour zone.

Sorry, I didn't realize I was going that fast.

Right. Just stay in the car for a few minutes. I'll be right back with these.

Okay. I'm giving you a citation for speeding. Now, you've got three options for how to proceed. One, you can plead guilty and pay the fine. Two, you can plead guilty but ask for a court appearance, and you'll have a chance to explain whatever reasons you had for driving almost 20 miles per hour over the speed limit. And maybe the judge will reduce your fine or the number of points. Okay? And your third option is you plead not guilty and you go to court and I go to court and we both tell our side of the story and the judge makes a decision. You got all that?

Yes.

That same information is printed on the citation ((pointing)) there, as well. ((Gives driver citation.))

Okay.

And here's your license. ((Gives driver license and registration.)) Now, I could've also given you a citation for reckless driving, which would be an additional $\$ 225$ fine, but I'm giving you a break.

Okay, thank you.

You have a safe evening, and watch your speed.

Figure 3: Prototypical Dialogue: Citation 
After creating prototypical dialogues, the next step is to develop a taskbased lesson using pedagogic tasks. The goal of pedagogic tasks is "on the one hand, to confront the need to engage naturalistic learning processes, while on the other, to allow the pedagogic process to be managed in a systematic manner" (Skehan, 1996, p. 58). Such pedagogic tasks are not to be broken up into minute segments to be analyzed synthetically; instead, attempts should be made to teach the tasks in holistic chunks (Van den Branden, 2006). The idea is that "people not only learn language in order to make functional use of it, but also by making functional use of it" (Van den Branden, 2006, p. 6). However, some modification should be made to genuine language. A materials developer or instructor could ask learners to listen to one or two samples of a recording of actual traffic stop interactions and then ask them to work in pairs, where one acts as the police officer and the other as the driver. This technique may work, but is unlikely to lead to a thorough understanding of what is involved in comprehending and successfully carrying out the task. To help ensure that learners of varying levels of proficiency have an opportunity to learn how to complete the task, the language and steps involved must be made accessible. Attention must be given to task complexity, task difficulty, and task conditions (Robinson, 2005, 2009), so that, in the instructor's judgement, the tasks are graded in an order of ascending complexity to the greatest extent possible.

Long (2014) recommends implementing a task-based lesson in a manner in which the pedagogic tasks increase in complexity. Below are five sample pedagogic tasks and one method for assessing learners' ability with the target tasks. (Discussing the degree to which these sample pedagogic tasks adhere to the principle of increasing complexity or the degree to which they are effective are important questions, but are beyond the scope of this article. They are included here simply as examples.)

\section{Introduce the topic}

- Tell students that the lesson is going to be about police traffic stops and ask students what sorts of things police officers stop drivers for (speeding, running red lights, failing to stop at a stop sign, broken headlight, etc.).

- Ask students what kinds of questions they think police officers ask drivers after they have stopped them.

- If students are willing to share their experiences, ask some to recount a traffic stop that they experienced (i.e., when and where they were stopped, why they were stopped, what the outcome was).

\section{Practice with police officer questions}

- Give students a handout with some questions that police officers typically ask (or use the questions that were generated in Task 1). Tell them to go through the questions and write the responses that they would give. What questions might they ask the officer? 


\section{Demonstrate target task}

- Play recording of a sample dialogue to give learners an understanding of the overall linguistic demands of the target task.

- Play the same sample dialogue in segments (e.g., play each segment of the police officer's turn, pausing to allow students to summarize it on a piece of paper).

- Play the segments a second time. After each segment, ask a volunteer to explain the police officer's turn. Then listen to the actual driver's response.

\section{Information-gap activity}

- Depending on students' L2 proficiency, use a genuine dialogue or an elaborated version.

- Student A reads the officer version of the dialogue to Student B.

- Student B is encouraged to ask clarification questions of Student A. After each turn, Student B supplies a summary of what the officer said to him or her.

- Students read full version of elaborated script together. Afterwards they answer questions: Why was the driver stopped? What was the outcome (warning or citation)? What does the driver have to do?

\section{Role play}

- Place students in groups of 3. Give them a sample scenario. Student A plays the role of the officer and Student B is the driver. Student C observes. When the exchange is complete, Student $C$ will summarize the following for Students A and B: why the driver was stopped, what the outcome was, and what the driver needs to do. Rotate roles, so all the students get an opportunity to play the role of the driver and the observer.

\section{Performance assessment ${ }^{6}$}

- Instructor A plays the role of police officer. Student plays role of driver. Instructor B observes. Student must negotiate a hypothetical traffic stop situation.

- Success on the task is to be determined in two ways:

a. Did the student demonstrate an ability to comply appropriately with the officer's requests and comments?

b. Post-interaction, was the student able to communicate answers to the following three questions (posed by Instructor B): Why were they stopped? What was the result of the stop? What do they need to do as a follow-up to the stop?

As the goal of these tasks is to give learners the opportunity to work on their ability to comprehend a police officer during a traffic stop (not to be able to talk like a police officer), the tasks have been structured to try to provide opportunities to comprehend that type of input. Instructors can repeat these 
tasks as they see fit, and modify them in any way that they think will enhance their learners' ability to improve or practice their comprehension for these situations.

\section{Conclusion}

Using the principles of TBLT, this article has outlined a method for creating prototypical dialogues from which language lessons can be developed to help learners improve their ability to communicate with police officers during a traffic stop. After identifying a target task via a learner needs analysis, information about the target task and/or samples (as authentic as possible) of the target task are obtained. By analyzing this information, the core linguistic needs for the task are identified, and around these, an instructor can create prototypical dialogues and pedagogic tasks. This in turn results in principled use of classroom time to most effectively focus learners' attention and practice on the tasks that are relevant to them.

In describing in detail how these steps were carried out for the target task of communicating with a police officer during a traffic stop, it has been shown that even for situations where gathering samples of authentic discourse might seem challenging, the use of domain experts will allow for the creation of materials that approximate the actual interaction so they will be useful to learners. The information provided by domain experts and the collection and analysis of target discourse samples is invaluable. It prevents reliance on intuition or imagination to provide language models for learners. Equally important, the use of a needs analysis to identify language-use situations that are relevant to learners prevents reliance on intuition or imagination in that area, as well.

Returning to van den Branden's question quoted at the outset, it is evident that effort is involved in implementing the TBLT approach. However, the effort is not beyond the scope of the ordinary: absent professional materials developers, a trained language instructor could follow these steps for this or other target tasks over the course of three to four weeks. Once done, the materials can be utilized repeatedly in most programs. Furthermore, the burden can be shared in language programs with more than one instructor. Additional tasks can be covered by individual instructors each semester, and a library of task-based materials will have been compiled in short order. This is, of course, more effortful than simply following lessons from a textbook, but as already noted, few, if any, commercially published textbooks provide adequate materials for real-life needs. Finally, most professional ESL/EFL instructors already supplement their lessons with materials that they create in their own time. To utilize that time to create materials following a principled method would be time better spent, while also allowing for the practice of target tasks that learners will actually face outside the classroom. Van den Branden also asked, "How can learners be stimulated?" It is unlikely that, in 
terms of classroom activities, there is anything more stimulating for serious language learners than to work with real-life tasks that have immediate and clear relevance for them, whether it is understanding what a doctor is saying about their child's illness, how to comprehend a physics lecture, or how to prepare for the possibility of a police traffic stop.

\section{Notes}

1. There are important sociocultural aspects of the police traffic stop interaction that probably should be addressed when teaching this target task. Different cultures have different attitudes toward police officers, and it would be useful to discuss this with learners, not only to inform more recent newcomers about the norms of their current environment but also to learn about these different attitudes. (For example, in Egypt a driver typically exits the vehicle during a traffic stop because to remain seated during the interaction with a police officer would be a sign of disrespect, whereas in the United States exiting the vehicle is perceived as a threatening action.) 2. The Internet can be a viable source of examples of authentic discourse surrounding a wide range of target tasks. For example, YouTube contains video recordings of large numbers of traffic stops. However, almost all of the videos that the author viewed were of extreme cases, which would not serve the purpose of creating pedagogic tasks that provide learners practice with a prototypical version of the interaction.

3. The four police departments that provided scripts of what police officers are trained to say during traffic stops were the Maryland State Police, University Park (MD) Police, Greenbelt (MD) Police, and the University of Maryland Police.

4. The author's interactions with the police officers provided a wealth of ancillary information regarding traffic laws and licenses that would be ideal supplements for discussion with learners before or after working on the language of interaction. This again highlights the value of using domain experts - whether they are police officers or biology professors - to inform the manner in which instructors address target tasks.

5. The linear schematic structure contains references to outcomes relevant to the state of Maryland (e.g., addressing an issued repair order within 10 days) and therefore directly relevant to the learners for whom these materials were created.

6. It is not the focus of this article to address performance/criterion-reference testing, but for a discussion of its implementation, see Bachman (2002), Brown and Hudson (2002), Messick (1994), and Norris, Brown, Hudson, and Yoshioka (1998).

\section{Acknowledgments}

I thank the police officers and departments who provided me with their time and expertise. In particular, I would like to thank the Greenbelt City Police Department and the University of Maryland Police Department. In addition, I thank Dr. Mike Long for his advice and support over the course of the project and two anonymous reviewers for their helpful suggestions.

\section{The Author}

Stephen P. O'Connell is a PhD student in the second language acquisition program at the University of Maryland, College Park. His primary research interests are the assessment of second language proficiency (particularly listening and speaking) and task-based language teaching and assessment.

\section{References}

Bachman, L. F. (2002). Some reflections on task-based language performance assessment. Language Testing, 19(4), 453-476. 
Bartlett, N. J. D. (2005). A double shot $2 \%$ mocha latte, please, with whip: Service encounters in two coffee shops and at a coffee cart. In M. H. Long (Ed.), Second language needs analysis (pp. 305-343). Cambridge, UK: Cambridge University Press.

Brown, J. D., \& Hudson, T. (2002). Criterion-referenced language testing. Cambridge, UK: Cambridge University Press.

Gass, S. M. (1997). Input, interaction and the second language learner. Mahwah, NJ: Lawrence Erlbaum.

Gass, S. M., \& Mackey, A. (2007). Input, interaction, and output in second language acquisition. In B. VanPatten \& J. Williams (Eds.), Theories in second language acquisition: An introduction (pp. 175-199). Mahwah, NJ: Lawrence Erlbaum.

Granena, G. (2008). Elaboration and simplification in Spanish discourse. IRAL, 46(2), 137-166.

Hoekje, B. J. (2007). Medical discourse and ESP courses for international medical graduates (IMGs). English for Specific Purposes, 26(3), 327-343.

Long, M. H. (1996). The role of the linguistic environment in second language acquisition. In W. Ritchie \& T. Bhatia (Eds.), Handbook of second language acquisition (pp. 413-468). San Diego, CA: Academic Press.

Long, M. H. (2005). Methodological issues in learner needs analysis. In M. H. Long (Ed.), Second language needs analysis (pp. 19-76). Cambridge, UK: Cambridge University Press.

Long, M. H. (2007). Texts, tasks, and the advanced learner. In M. H. Long (Ed.), Problems in SLA (pp. 119-138). Mahwah, NJ: Lawrence Erlbaum.

Long, M. H. (2014). Second language acquisition and task-based language teaching. Oxford, UK: Wiley-Blackwell.

Mackey, A., Gass, S., \& McDonough, K. (2000). How do learners perceive interactional feedback? Studies in Second Language Acquisition, 22(4), 471-497.

McDonough, K. (2005). Identifying the impact of negative feedback and learners' responses on ESL question development. Studies in Second Language Acquisition, 27(1), 79-103.

Messick, S. (1994). The interplay of evidence and consequences in the validation of performance assessments. Educational Researcher, 23(2), 13-23.

Nielsen, K. (2010). Casa de Maryland needs analysis. Unpublished manuscript, University of Maryland, College Park.

Norris, J. M., Brown, J. D., Hudson, T., \& Yoshioka, J. (1998). Designing second language performance assessments. Honolulu, HI: University of Hawaii Press.

Robinson, P. (2005). Cognitive complexity and task sequencing: Studies in a componential framework for second language task design. IRAL, 43(1), 1-32.

Robinson, P. (2009). Syllabus design. In M. H. Long \& C. J. Doughty (Eds.), Handbook of language teaching (pp. 294-310). Oxford, UK: Blackwell.

Skehan, P. (1996). A framework for the implementation of task-based instruction. Applied Linguistics, 17(1), 38-62.

Van den Branden, K. (2006). Introduction: Task-based language-teaching in a nutshell. In K. Van den Branden (Ed.), Task-based language education: From theory to practice (pp. 1-16). Cambridge, UK: Cambridge University Press.

Van den Branden, K., Bygate, M., \& Norris, J. M. (2009). Task-based language teaching: Introducing the reader. In K. Van den Branden, M. Bygate, \& J. M. Norris (Eds.), Task-based language teaching: A reader (pp. 1-13). Amsterdam, The Netherlands: John Benjamins.

Ventola, E. (1983). Contrasting schematic structures in service encounters. Applied Linguistics, $4(3), 242-258$.

Wong, J. (2002). "Applying" conversation analysis in applied linguistics: Evaluating dialogue in English as a second language textbooks. IRAL, 40(1), 37-60. 